\title{
Emodin regulates cell cycle of non-small lung cancer (NSCLC) cells through hyaluronan synthase 2 (HA2)-HA-CD44/receptor for hyaluronic acid-mediated motility (RHAMM) interaction-dependent signaling pathway
}

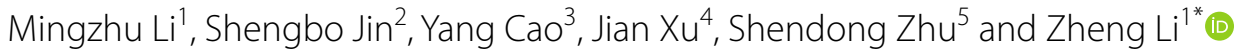

\begin{abstract}
Background: Non-small cell lung cancers (NSCLC) account for most cases of lung cancer. More effort is needed to research new drug and combination therapies for this disease. An anthraquinone derivative, emodin shows anticancer potency. We hypothesis that emodin suppresses lung cancer cells through hyaluronan (HA) synthase 2-HA-CD44/ receptor for hyaluronic acid-mediated motility (RHAMM) interaction-dependent signaling pathway mediated cell cycle regulation.
\end{abstract}

Methods: We tested the effect of emodin on viability, apoptosis, and HA secretion of 5 NSCLC cell lines. We used NSCLC cells A549 for two rounds of knockdown study: (1) knocking down either the synthases (HAS2 and HAS3) or the receptors (CD44 and RHAMM); (2) knocking down either HAS2 or HAS3. Then determined the effect of emodin on viability, HA secretion, cell cycle, and expression of cyclin proteins.

Results: Emodin suppressed viability and HA secretion of all 5 NSCLC cell lines except for HA secretion of H460. Emodin had a slight apoptosis induction effect on all cell lines and was not different among cell lines. The knockdown of either the synthases or the receptors blocked emodin effects on viability while the knockdown of HAS2 block emodin effects but not HAS3. Emodin increased cells in the G1/G0 phase, and decreased cells in the S and G2/M phase by down-regulating cyclin A and B and up-regulating cyclin C, D, and E. HAS2 knockdown blocked the effects of emodin on the cell cycle.

Conclusions: This study demonstrated that emodin regulates the cell cycle of NSCLC cells through the HAS2-HACD44/RHAMM interaction-dependent signaling pathway.

Keywords: NSCLC, HAS, CD44, RHAMM, Cell cycle

\footnotetext{
*Correspondence: li189zheng@163.com

${ }^{1}$ Department of Integrated Traditional Chinese and Western Medicine

Medical Oncology, Cancer Hospital of China Medical University, Liaoning Cancer Hospital \& Institute, Liaoning, China

Full list of author information is available at the end of the article
}

\begin{abstract}
Background
Lung cancer results in most cancer death among males and the second most cancer death among females in 2020 in the world [1]. Lung cancer rates are reducing year by year in most of the developed countries, such as the United States, United Kingdom, and Australia, but are elevating in low- and middle-income countries where
\end{abstract}

(c) The Author(s) 2021. This article is licensed under a Creative Commons Attribution 4.0 International License, which permits use, sharing, adaptation, distribution and reproduction in any medium or format, as long as you give appropriate credit to the original author(s) and the source, provide a link to the Creative Commons licence, and indicate if changes were made. The images or other third party material in this article are included in the article's Creative Commons licence, unless indicated otherwise in a credit line to the material. If material is not included in the article's Creative Commons licence and your intended use is not permitted by statutory regulation or exceeds the permitted use, you will need to obtain permission directly from the copyright holder. To view a copy of this licence, visit http://creativeco mmons.org/licenses/by/4.0/. The Creative Commons Public Domain Dedication waiver (http://creativecommons.org/publicdomain/ zero/1.0/) applies to the data made available in this article, unless otherwise stated in a credit line to the data. 
smoking occurred later [1]. Non-small cell lung cancers account for about $85 \%$ of lung cancers, whereas small cell lung cancers only occupy approximately $15 \%$ of lung cancers [2]. Over the past two decades, a great improvement has been achieved in the clinical therapy of non-small cell lung cancer (NSCLC) [3], but, so far, the low rates of cure and survival for NSCLC patients urge more effort to research new drug and combination therapies for this disease.

Recently, many studies were developing naturally occurring compounds for clinical use [4-8]. An anthraquinone derivative, emodin (1,3,8-trihydroxy-6-methylanthraquinone), which is identified in Cassia obtusifolia [9], Aloe vera [10], Polygonum multiflorum [11], Rheum palmatum [12], and Polygonum cuspidatum [13], was thought to have multiple pharmacological effects. Emodin has been proved to have anti-cancer and anti-inflammatory properties $[14,15]$. A study in breast cancer cell lines showed that emodin can inhibit MCF-7 growth and induce its apoptosis. In addition, liver cancer cells were also suppressed by emodin [16]. Emodin is included in some clinical traditional medicine prescriptions used for lung cancer in some Chinese hospitals. Therefore, we suggested that emodin might have inhibition toward lung cancer cells.

Hyaluronan (HA) is a molecule in the cancer microenvironment that is associated with malignancy. Transmembrane HA synthases 1-3 (HAS1, HAS2, or HAS3) is responsible for the synthesis of $\mathrm{HA}$ in mammalian cells [17]. After processed by hyaluronidases, mechanical forces, HA becomes a signaling molecule that can regulate inflammatory and tumorigenic [18]. HA interacts with cells through several cell surface receptors, the most critical of which is CD44 and the receptor for hyaluronic acid-mediated motility (RHAMM). Binding of HA to CD44/RHAMM on cells regulates cell proliferation by affecting a variety of downstream signaling pathways $[19,20]$. Studies have revealed that HA is overexpressed in lung carcinoma over normal lung tissue [21]. Clinical data also suggested HA expression is associated with a higher frequency of recurrence [22]. CD44 and RHAMM are also overexpressed in lung cancer [23] and have been proved to correlate with worse cancer outcomes [24]. HA-CD44/RHAMM signal pathway has been reported to affect lung cancer proliferation [25].

Our preliminary experiments found that the HA expression of non-small lung cancer cells was affected by emodin, thus we hypothesis that emodin affects nonsmall lung cancer cells through HA CD44/RHAMM signaling pathway. In this study, we demonstrated the hypothesis and then knocked down critical targets of the HA CD44/RHAMM signaling pathway to explore the exact target of emodin. As we suggested the effect of emodin is mediating by HA cell cycle regulation, we analyzed the cell cycle and tested the cyclin proteins. Our study aims to deepen the understanding of the role of HA CD44/RHAMM signaling pathway in non-small lung cancer cells and develop emodin as a novel drug for the treatment of lung cancer.

\section{Methods}

Cell lines and cell culture

A549 $\left(\right.$ ATCC $^{\circledR}{\text { CCL- }-185^{\mathrm{TM}}}^{\mathrm{T}}$ ), H520 (ATCC ${ }^{\circledR} \mathrm{HTB}^{-182^{\mathrm{TM}}}{ }$ ), H1975 (ATCC $^{\circledR}$ CRL-5908 $^{\text {TM }}$ ), H1299 (ATCC $^{\circledR}$ CRL$5803^{\text {TM }}$ ), H460 (ATCC ${ }^{\circledR}$ HTB-177) were obtained from ATCC (Washington, USA). A549was cultured in Dulbecco's Modified Eagle Media (DMEM) with 10\% Fetal Bovine Serum (FBS) $\left(\right.$ ATCC $^{\circledR} 30-2020^{\mathrm{TM}}$ ). H520, H1975, H1299, and H460were cultured in RPMI-1640 medium $\left(\right.$ ATCC $^{\circledR} 30-2001^{\mathrm{TM}}$ ) with $10 \%$ FBS. Cell lines were cultured in a cell culture incubator with a humidified atmosphere of $5 \% \mathrm{CO}_{2}$ at $37^{\circ} \mathrm{C}$.

\section{MTT assay}

Cell viability was determined using The cells were plated in 96-well plates at $4 \times 10^{3} /$ well. Cells were cultured in the FBS-free medium for $24 \mathrm{~h}$ for starvation. After exposure to emodin for $24 \mathrm{~h}$, methylthiazoletetrazolium (MTT, Abcam, Cambridge, UK) was incubated with the cells $(40 \mu \mathrm{L} /$ well) for $4 \mathrm{~h}$. A microplate reader was used to read the plate at $490 \mathrm{~nm}$.

\section{ELISA assay}

The concentration of $\mathrm{HA}$ in the culture medium was determined by using Hyaluronan Quantikine ELISA Kit (Minneapolis, MN, US). The apoptosis of the cells was also determined by ELISA assay. The cells were plated in 96-well plates $(3-5 \times 103 /$ well $)$ for $12 \mathrm{~h}$ and were treated as described before. The apoptosis assays were then performed using Cell Death Detection ELISA plus (Roche, Indianapolis, IN, USA), which monitors DNA fragmentation. The absorbance was measured at $490 \mathrm{~nm}$ using the Multiskan $^{\mathrm{TM}}$ FC Microplate Photometer. We prepared a positive control for each cell line by inducing cell death through incubating cells at $55 \circ \mathrm{C}$ for $20 \mathrm{~min}$.

\section{Cell transfection}

Gene knockdown in A549 was achieved by siRNA transfection. The transfection method was described previously [26]. Briefly, cells were transfected with siRNA or negative siRNA using Lipofectamine ${ }^{\circledR} 2000$. The concentration and time of transfection for the siRNA was $50 \mathrm{nM}$ for $72 \mathrm{~h}$. The expression of target proteins in cells was validated by western blotting assay. The Lipofectamine ${ }^{\circledR}$ 2000 kite, HAS2 siRNAs (AM16708), HAS3 siRNA (AM16708), CD44 siRNA (AM16708), and negative 
siRNA (AM4611) were obtained from ThermoFisher Scientific (Waltham, MA, USA). RHAMM siRNA (sc40181) were obtained from Santa Cruz Biotechnology (Dallas, TX, US).

\section{Cell cycle assay}

The cell cycle was determined using flow cytometry with propidium iodide (PI) staining, which was described previously [27]. $4 \times 10^{6}$ suspended cells were fixed with precold $70 \%$ ethanol for $2 \mathrm{~min}$ at $4{ }^{\circ} \mathrm{C}$. The cells were then mixed with $0.02 \mathrm{mg} / \mathrm{mL}$ DNAse-free RNAse A with $0.2 \mathrm{mg} / \mathrm{mL} 0.1 \%$ Triton X-100 in cold PBS at $37{ }^{\circ} \mathrm{C}$ for 30 min. Cells were detected with BD FACSCalibur (Becton Dickinson. San Jose, CA, USA).

\section{Western blotting}

Protein expression was determined by western blotting, which was described previously [28]. Cells were lysed with RIPA buffer with protease inhibitor (Sigma-Aldrich, USA). Total protein concentrations were tested by BCA. SDS gel electrophoresis was conducted to separate the proteins with a loading amount of $30 \mu \mathrm{g} / \mathrm{well})$. Then the proteins were electrically transferred onto polyvinylidene difluoride membranes $(0.2-\mu \mathrm{m})$. The membranes were incubated with a blocking buffer (5\% skimmed milk in TBS). Membranes were then incubated with primary (1:1000 dilution of BSA, $4{ }^{\circ} \mathrm{C}$, overnight) and secondary antibodies (1:3000 dilution of BSA, room temperature, $2 \mathrm{~h}$ ). ECL was used to visualize the proteins. The proteins were quantified by Image Studio ${ }^{\mathrm{TM}}$ Lite (Lincoln, NE, US). Anti-cyclin A antibody (sc-271,682), Anti-Cyclin B antibody (ab72), Anti-Cyclin C antibody (ab85927), AntiCyclin D1 antibody (ab40754), Anti-Cyclin E1 antibody (ab133266), and all the secondary antibodies were purchased from Abcam (Cambridge, UK).

\section{Statistics and plotting}

T-test or one-way ANOVA and Dunnett's post hoc tests were used to analyze the significance of the difference. $\mathrm{p}$-value greater than 0.05 was considered a significant difference.

\section{Results}

\section{Emodin suppressed the viability of lung cancer cells} with different potency

Emodin at $20-80 \mu \mathrm{M}$ was reported to suppress the viability of liver cancer cells [16]. Our preliminary data showed that emodin at $10-100 \mu \mathrm{M}$ suppressed the viability of lung cancer cells with different potency (data not shown). In this study, we used a lower concentration range (1-30 mM) aiming to distinguish the potency of different cell lines. We used MTT assay to determine the effect of emodin at $1-30 \mu \mathrm{M}$ on cell viability of five lung cancer cell lines A549, H520, H1975, H1299, and H460. MTT assay is commonly used for cancer pharmacological studies [29]. Results show that A549 was the most sensitive cell line with an effective concentration of $5 \mu \mathrm{M}$. Viability of A549 was dose-dependently inhibited by emodin at $5-30 \mathrm{mM}$. H520 was the second most sensitive cell line with an effective concentration of $15 \mu \mathrm{M}$. Viability of $\mathrm{H} 520$ was dose-dependently inhibited by emodin at 15-30 mM. The other three cell lines, including H1975, H1299, and H460, showed a significant decrease in cell viability only when the concentration of emodin reached $30 \mu \mathrm{M}$ (Fig. 1a). Besides, we also determined the effect of emodin on apoptosis. Emodin at $20-30 \mathrm{mM}$ had a slight apoptosis induction effect $(<20 \%)$ on all cell lines. The apoptosis induction of emodin was not different among cell lines (Fig. 1b). Therefore, we suggested the difference in the viability of cell lines resulted from the effect of emodin on cell proliferation. Emodin at $30 \mu \mathrm{M}$ showed the most difference in the effect on viability among lung cancer cell lines, thus it was used in the subsequent study.

\section{Emodin suppressed the secretion of HA in lung cancer cell lines}

To demonstrate our hypothesis, we tested the effect of emodin on the ability of lung cancer cells to produce HA. The concentrations of HA in the culture media, which we measured by ELISA, indicated the expression of HA. Results showed that Emodin at $30 \mu \mathrm{M}$ suppressed HA secretion in all lung cancer cell lines tested except for $\mathrm{H} 460$, inferring that emodin might regulate HA generation. A549 was the most sensitive cell line with a suppression rate of over $75 \%$. (Fig. 1b) As A549 was the most sensitive to emodin both in cell viability and HA secretion, it was used in the subsequent knockdown study.

\section{The sensitivity of viability suppression was associated} with the sensitivity of suppression of the HA secretion

Among the five lung cancer cell lines tested, we found a rough correlation between the suppression of emodin on cell viability and that on HA secretion (Fig. 2a). A549 and $\mathrm{H} 520$ had a relatively higher suppression rate of emodin on cell viability, which was also more sensitive in terms of emodin secretion suppression. This suggested a potential association between emodin suppression on HA generation and that on cell viability.

\section{Emodin suppressed HAS2 but not HAS3, CD44, and RHAMM in lung cancer cells}

We determined the expression level of HAS2, HAS3, CD44, and RHAMM in lung cancer cell lines except for CD44 in H1975 and HAS2 in H460 which might be too low to be detected in our experiment. Results showed that emodin decreased the expression of HAS2 

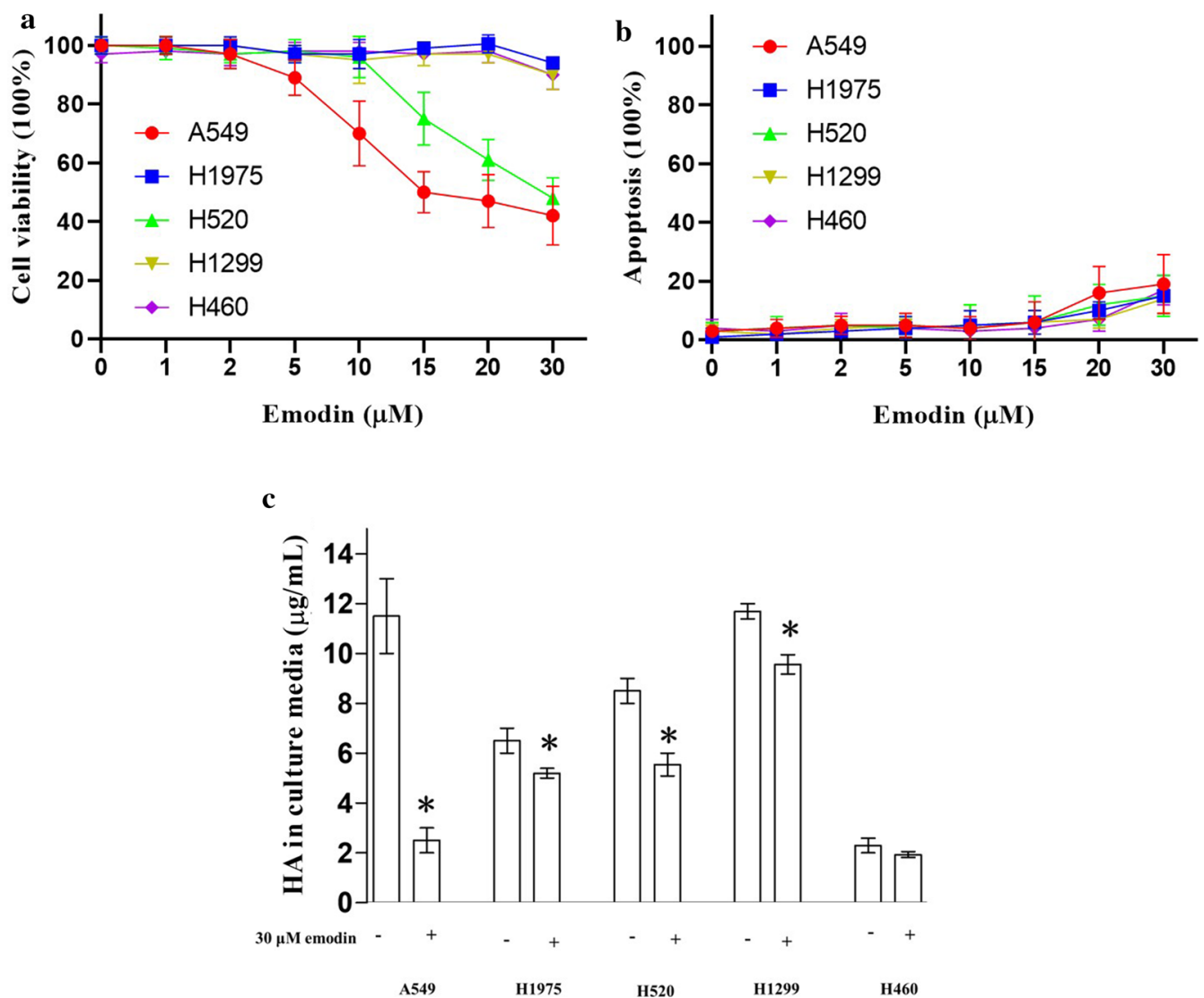

Fig. 1 Effect of emodin on the cell viability and HA secretion of lung cancer cells. Lung cancer cell lines were exposed to 0-30 $\mu \mathrm{M}$ emodin for 24 $\mathrm{h}$ before the MTT and ELISA assay. a Suppression of emodin on cell viability of lung cancer cell lines. A549 was the most sensitive cell line with an effective concentration of $5 \mu \mathrm{M}$. Viability of A549 was dose-dependently inhibited by emodin at 5-30 mM. H520 was the second most sensitive cell line with an effective concentration of $15 \mu \mathrm{M}$. Viability of $\mathrm{H} 520$ was dose-dependently inhibited by emodin at 15-30 mM. The other three cell lines, including $\mathrm{H} 1975, \mathrm{H} 1299$, and $\mathrm{H} 460$, showed a significant decrease in cell viability only when the concentration of emodin reached $30 \mu \mathrm{M}$. $\mathbf{b}$ The effect of emodin on apoptosis. Emodin at 20-30 mM had a slight apoptosis induction effect (<20\%) on all cell lines. The apoptosis induction of emodin was not different among cell lines. c The effect of emodin on HA secretion of lung cancer cells. Emodin at $30 \mu \mathrm{M}$ suppressed HA secretion in all lung cancer cell lines tested except for $\mathrm{H} 460$, inferring that emodin might regulate HA generation. A549 was the most sensitive cell line with a suppression rate of over $75 \%$. "* marks the significant difference $(p<0.05)$ compare with the control $(0 \mu \mathrm{M}$ or " $-")$

in lung cancer cells but had no significant effect on HAS3, CD44, and RHAMM. Notably, A549 had the highest expression level of HAS2 and also had the largest decrease in HAS2 level after exposed to emodin (Fig. 2b-f).

\section{Effect of knockdown of HAS2, HAS3, CD44, and RHAMM on A549}

To test the hypothesis, we tried to block the HA-CD44/ RHAMM signaling pathway by knocking down HAS2, HAS3, CD44, and RHAMM in A549. Western blocking confirmed that the protein expressions of HAS2, HAS3, CD44, and RHAMM were reduced in A549.
The knockdown resulted in a dramatic decrease in HA secretion and also inhibited the viability by about $60 \%$. The exposure of emodin further decrease the HA secretion but failed to impact the viability of the cells (Fig. 3).

\section{Effect of knockdown of HAS2 and HAS3 on A549}

To specify the exact target of emodin, we first knocked down the expression of both HAS2 and HAS3 in A549. The knockdown of HAS2 and HAS3 decreased the viability and HA secretion of A549 by about $60 \%$ and $80 \%$ respectively. Then we exposed the cells to emodin and found that knockdown of HAS2 and HAS3 resulted 

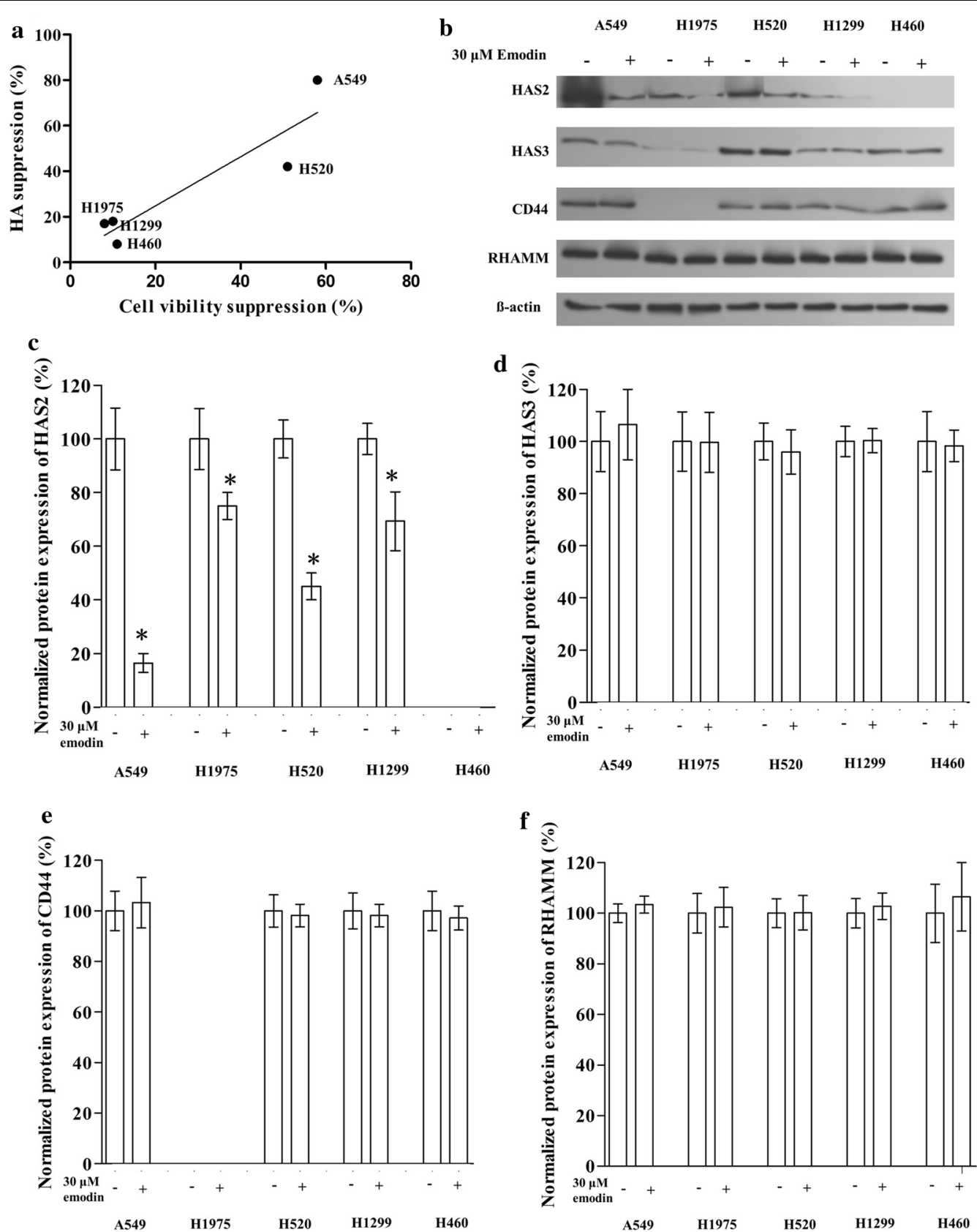

Fig. 2 Effect of emodin on the HA-CD44/RHAMM signaling pathway in lung cancer cell lines. Cells were exposed to $30 \mu \mathrm{M}$ emodin for $24 \mathrm{~h}$ before the western blotting assay. a The suppression rate of emodin on cell viability was plotted vs. suppression rate of emodin on HA secretion. $\mathbf{d}$ Representative image of western blotting. c-f The effect of emodin on the protein expression of HAS2, HAS3, CD44, and RHAMM in lung cancer cell lines (Bar chart for western blotting). "**" marks the significant difference $(p<0.05)$ compare with the control (0 $\mu \mathrm{M}$ or " $-")$

(See figure on next page.)

Fig. 3 The effect of emodin on the HA-CD44/RHAMM signaling pathway knocked down A549 cells. The expression of HAS2 and HAS3 (HAS2/3) or CD44 and RHAMM (CD44/RHAMM) were knocked down in A549 cells. a The effect of emodin on viability. The transfected cells were exposed to $30 \mu \mathrm{M}$ emodin for $24 \mathrm{~h}$ before the MTT assay. $\mathbf{b}$ The effect of emodin on HA secretion of transfected A549 cells. c Representative image of western blotting. $\mathbf{d}-\mathbf{g}$ The effect of emodin on the protein expression of HAS2, HAS3, CD44, and RHAMM in transfected A549 (Bar chart for western blotting). "*" marks the significant difference $(p<0.05)$ compare with the vehicle control (" $-")$ 


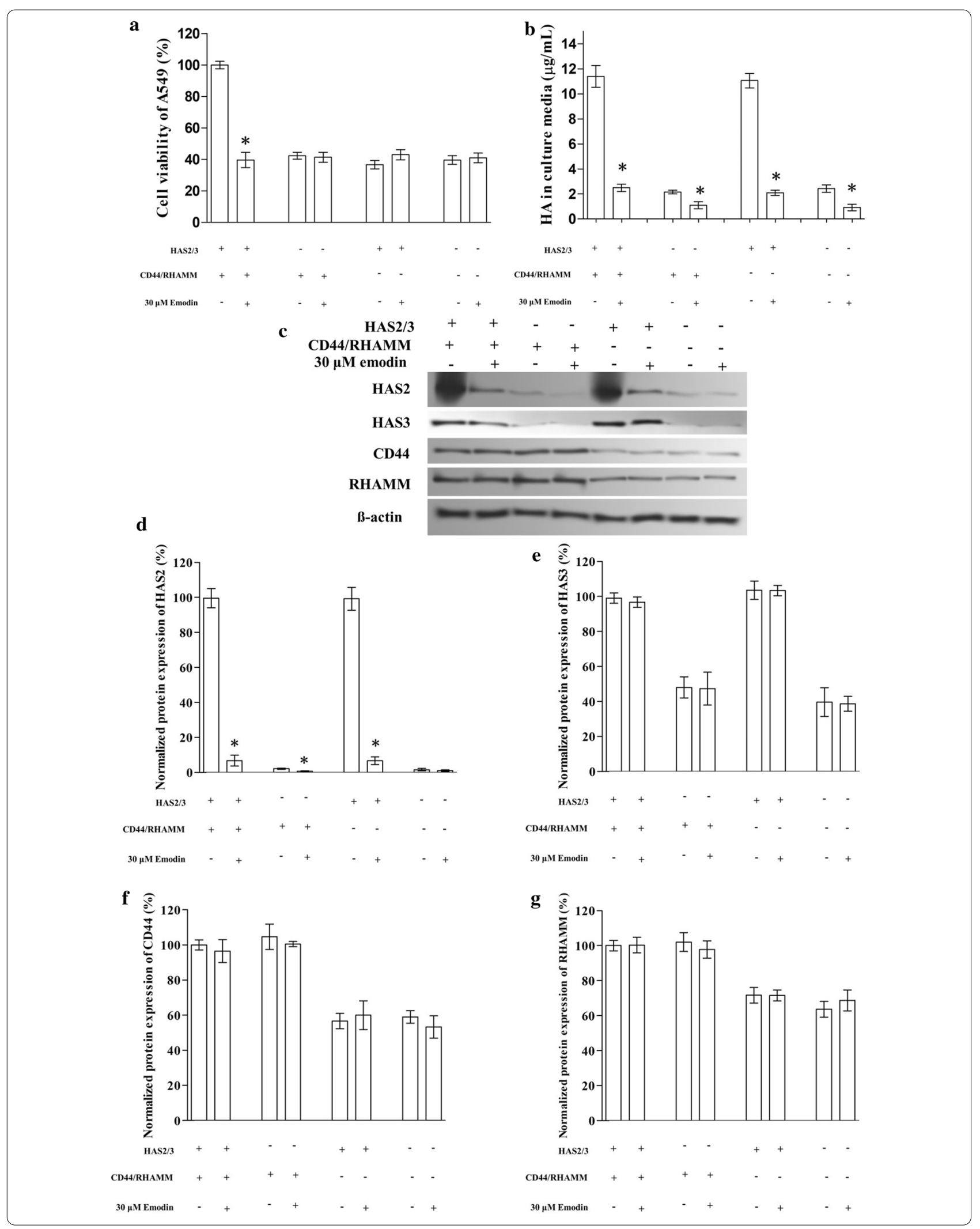


in the decrease in HA secretion and the resistance of A549 to emodin viability suppression (Fig. 3).

\section{Effect of knockdown of CD44 and RHAMM on A549}

Next, we knocked down the expression of two downstream targets, CD44 and RHAMM, in A549. The knockdown of CD44 and RHAMM decreased the viability to a similar level as HAS2 and HAS3 knockdown cells while HA secretion was not affected by the knockdown of CD44 and RHAMM. After exposed to emodin, HA secretion decreased by more than $80 \%$ but the viability of CD44 and RHAMM knocked down A549 cells was not affected significantly. (Fig. 3). Hence, we suggested that emodin impact the expression of HAS2 or HAS3 but not CD44 or RHAMM.

\section{Emodin suppressed the viability of A549 by suppressing HAS2 expression but not HAS3}

To further specify the exact target of emodin, we knocked down the expression of either HAS2 or HAS3 in A549 respectively. The western blotting confirmed that that knockdown was successful but the decrease of HAS2 (by about $90 \%$ ) was more dramatic than the decrease of HAS3 (by about 50\%) (Fig. 4c-e). The knockdown of HAS2 or HAS3 showed a similar effect: both the viability and HA secretion of A549 decreased by about 40\%, but after the cells were exposed to emodin, the viability and HA secretion significantly decreased only in HAS2 knocked down cells but not in HAS3 knocked down cells (Fig. 4a, b).

\section{Emodin affect the cell cycle of A549 through HAS2}

According to viability results, emodin at $30 \mu \mathrm{M}$ suppressed the viability of A549, which, we suggested, was associated with the cell cycle regulation. We analyzed the cell cycle of A549 cells. In negative siRNA groups, emodin significantly increased cells in the G1/G0 phase and decreased cells in the $S$ and G2/M phase. This result indicated that emodin arrested cell proliferation. HAS2 knockdown showed similar effects on the cell cycle, causing an increase in cells in the G1/G0 phase, and a decrease in cells in the $\mathrm{S}$ and $\mathrm{G} 2 / \mathrm{M}$ phase. The knockdown of HAS2 also blocked the effect of emodin, suggesting that emodin affects the cell cycle of A549 through HAS2 (Fig. 5).

Emodin regulated cyclin proteins through emodin in A549 To further explore the mechanism of emodin regulation on the cell cycle, we determined the expression of key regulatory proteins of the cell cycle by western blotting: cyclin A, cyclin B, cyclin C, cyclin D, and cyclin E. In negative siRNA control groups, emodin decreased the expression of cyclin A and cyclin B and increased cyclin
C, cyclin D, and cyclin E. The HAS2 knockdown also emodin decreased the expression of cyclin A and cyclin $\mathrm{B}$ and increased cyclin $\mathrm{C}$, cyclin $\mathrm{D}$, and cyclin $\mathrm{E}$. In the HAS2 knockdown groups, these cyclin proteins were not changed by emodin, proving that HAS2 mediated the effect of emodin on the cell cycle by regulating cyclin proteins (Fig. 6).

\section{Discussion}

This study reveals the inhibition of emodin against the proliferation of non-small lung cancer cells. MTT assay, which is a common assay used in cancer cell viability studies [29], was used to screen five cell lines at different concentrations. The sensitive concentration range of emodin toward non-small lung cancer cells is similar to that of liver cancer cell line SMMC-7721, whose viability was suppressed by $20 \mu \mathrm{M}$ emodin by about $30 \%$ [16]. Yet, by comparing the effect of emodin on five non-small lung cancer cell lines, we found that different cell lines we tested had different sensitivity toward emodin. This can account for the fact that the clinical treatment of emodin-containing traditional medicine only effective in some cases.

The non-small lung cancer cell lines used in this study are commonly used non-small-cell lung cancer cell lines derived from different sources. A549 cell line was developed from cancerous lung tissue in the explanted tumor of a 58-year-old caucasian male [30]. The H1975 cell line is used for the study of drug resistance based on some special mutations [31]. The H520 cell line was derived taken from a patient with squamous cell carcinoma of the lung. H520 cells express greatly reduced levels of p53 mRNA relative to normal lung tissue [32]. H1299 is a human non-small cell lung carcinoma cell line derived from the lymph node [33]. H1299 has a homozygous partial deletion of the TP53 gene [34]. H460 is a highly lymphomatous metastatic subline of a human non-small lung cancer cell line [35]. We believe using multiple cell lines can better demonstrate the effect of emodin is common among many Non-small-cell lung cancer cell lines. Besides, with multiple cell lines, we can select the most sensitive cell line for the subsequent study as it facilitates our observation. We did not know what caused the difference in the effect of emodin on HA secretion, but we found a rough correlation between the suppression of emodin on cell viability and that on HA secretion (Fig. 2a). A549 and H520 had a relatively higher suppression rate of emodin on cell viability, which was also more sensitive in terms of emodin secretion suppression. This suggested a potential association between emodin suppression on HA generation and that on cell viability. The effect of $\mathrm{HA}$ is largely through the activation of CD44/RHAMM $[19,20]$. Thus, we hypothesis that 


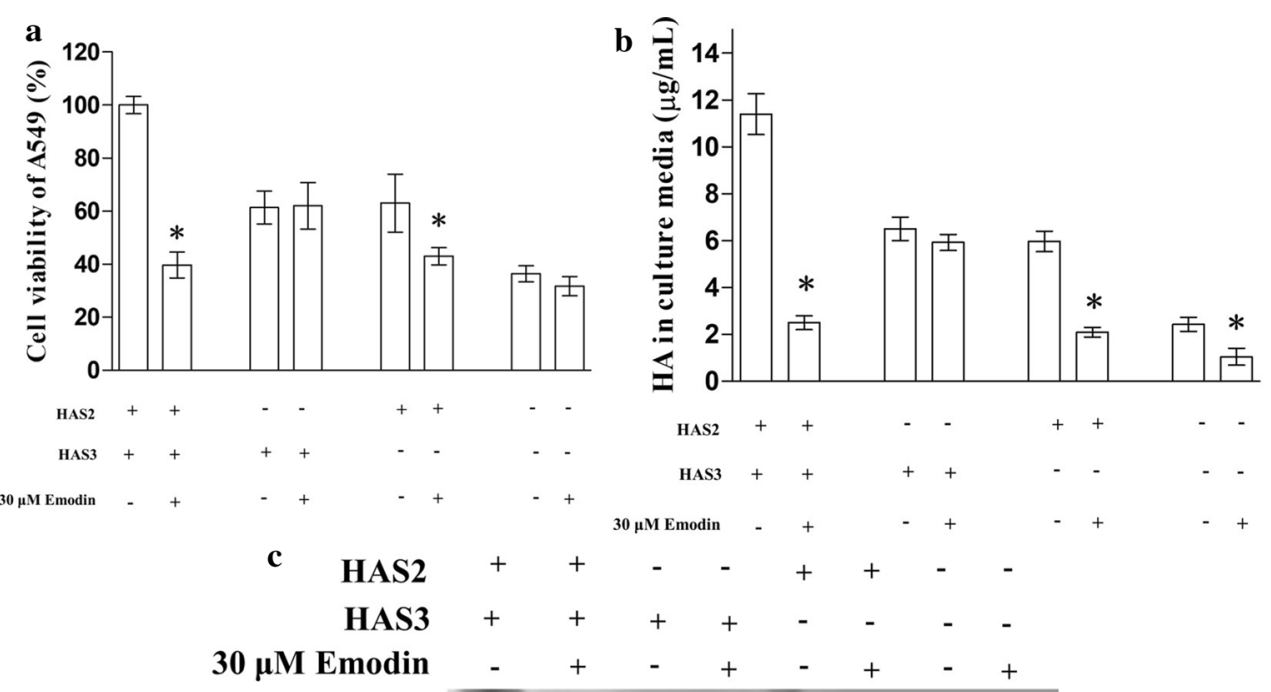

d

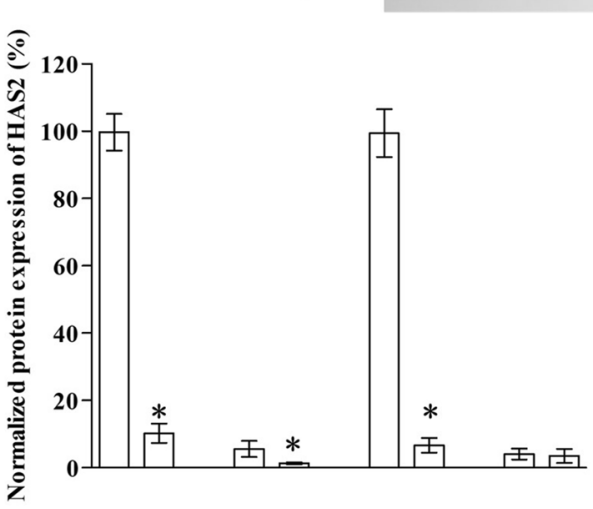

e

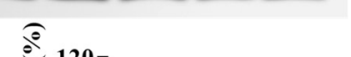

HAS2

HAS3

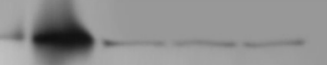

B-actin

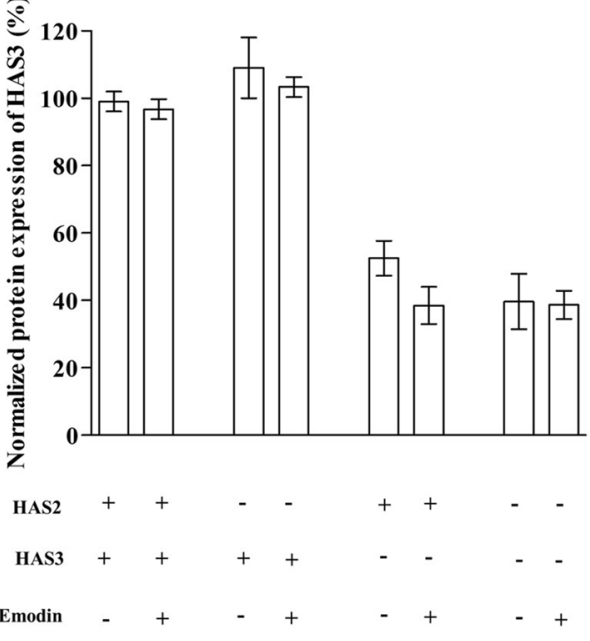

Fig. 4 The effect of emodin on HAS2 or HAS3 knocked down A549 cells. The expression of HAS2 or HAS3 was knocked down in A549 cells. a The effect of emodin on the viability of knocked down A549 cells. The transfected cells were exposed to $30 \mu \mathrm{M}$ emodin for $24 \mathrm{~h}$ before the MTT assay. $\mathbf{b}$ The effect of emodin on HA secretion of transfected A549 cells. c Representative image of western blotting. DE. The effect of emodin on the protein expression of HAS2 and HAS3, in transfected A549 (Bar chart for western blotting). "*" marks the significant difference $(p<0.05)$ compare with the vehicle control ("-")

emodin affects non-small lung cancer cells through the HA CD44/RHAMM pathway.

We designed a protein knockdown experiment to explore the target of emodin. We selected A549, in which we suggested HA CD44/RHAMM pathway might play the most role among cell lines we tested, for the knockdown experiments because it is the most sensitive cell line toward emodin in the MTT assay and HA detection. In the preliminary study, for some reason, A549 was not able to survive when we knocked down HAS1. A previous study studying HA CD44/RHAMM pathway in lung cancer cells only knocked down HAS2 and HAS3 as us [25], we suggested they might also come across the same issue. In the present study, there were two rounds of the knockdown experiment, in the first round, we knocked down either the synthases (HAS2 and HAS3) or the receptors (CD44 and RHAMM). Results showed that either of the knockdowns blocked the effects of emodin 


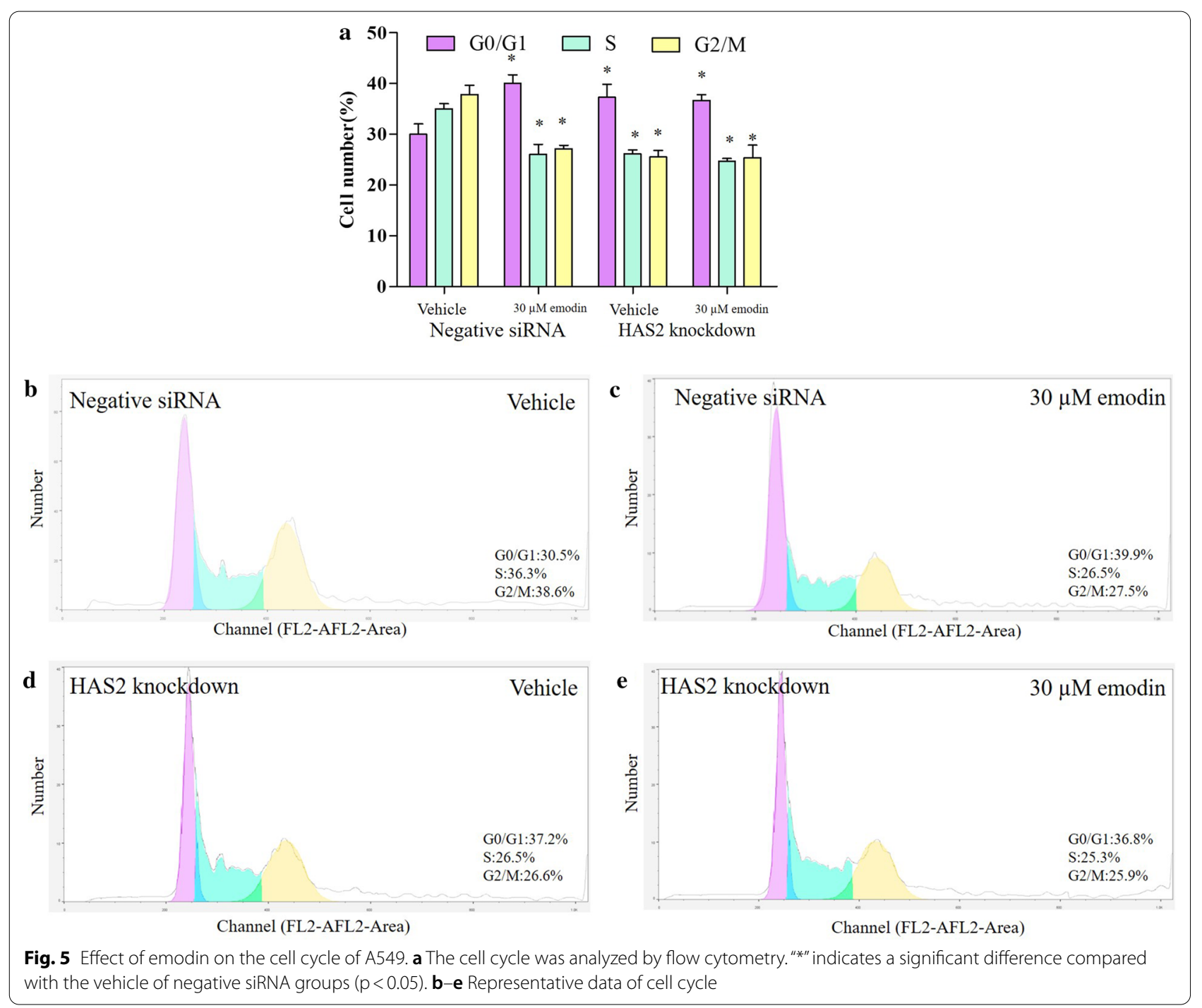

on A549 viability completely, suggesting that those targets were critical for the pharmacological effects of emodin. Either of the knockdowns also led to the decrease of cell viability indicating that the HA CD44/RHAMM pathway promotes cell viability, which is consistent with a previous study [25]. In the second round of the knockdown experiment, we knocked down either one of the synthases, HAS2 or HAS3. Results revealed that the effect of emodin was only associated with the expression of HAS2, indicating that emodin suppressed only HAS2 but not HAS3. Regarding the data of the other lung cancer cell lines we tested, in H1975, the expression of CD44 was low, indicating the absence of HA CD44/RHAMM pathway; while in $\mathrm{H} 1299$ and H460, the expression of HAS2 was low, resulting in the low sensitivity of the cell toward emodin, which agreed with the finding that emodin affected the cells through HAS2-HA-CD44/RHAMM pathway. Nevertheless, if HAS1 is affected by emodin was not explored in this study.

HA-CD44/RHAMM signal was thought to be associated with the cell cycle in tissue and cells [36, 37]. Flow cytometry with propidium iodide (PI) staining is commonly used in a cancer cell study [38]. Here we found that emodin significantly increased cells in the G1/G0 phase, and decreased cells in the $S$ and $G 2 / M$ phase. Cells in the G0/G1 phase were supposed to stop growing for other biological activities [39], while the S/G2/M phase is for cell proliferation [40]. This result indicated that emodin arrested cell proliferation. HAS2 knockdown showed similar effects on the cell cycle, causing an increase in cells in the G1/G0 phase, and a decrease in cells in the $\mathrm{S}$ and $\mathrm{G} 2 / \mathrm{M}$ phase. The knockdown of HAS2 also blocked the effect of emodin, suggesting that emodin affected the cell cycle of A549 through 


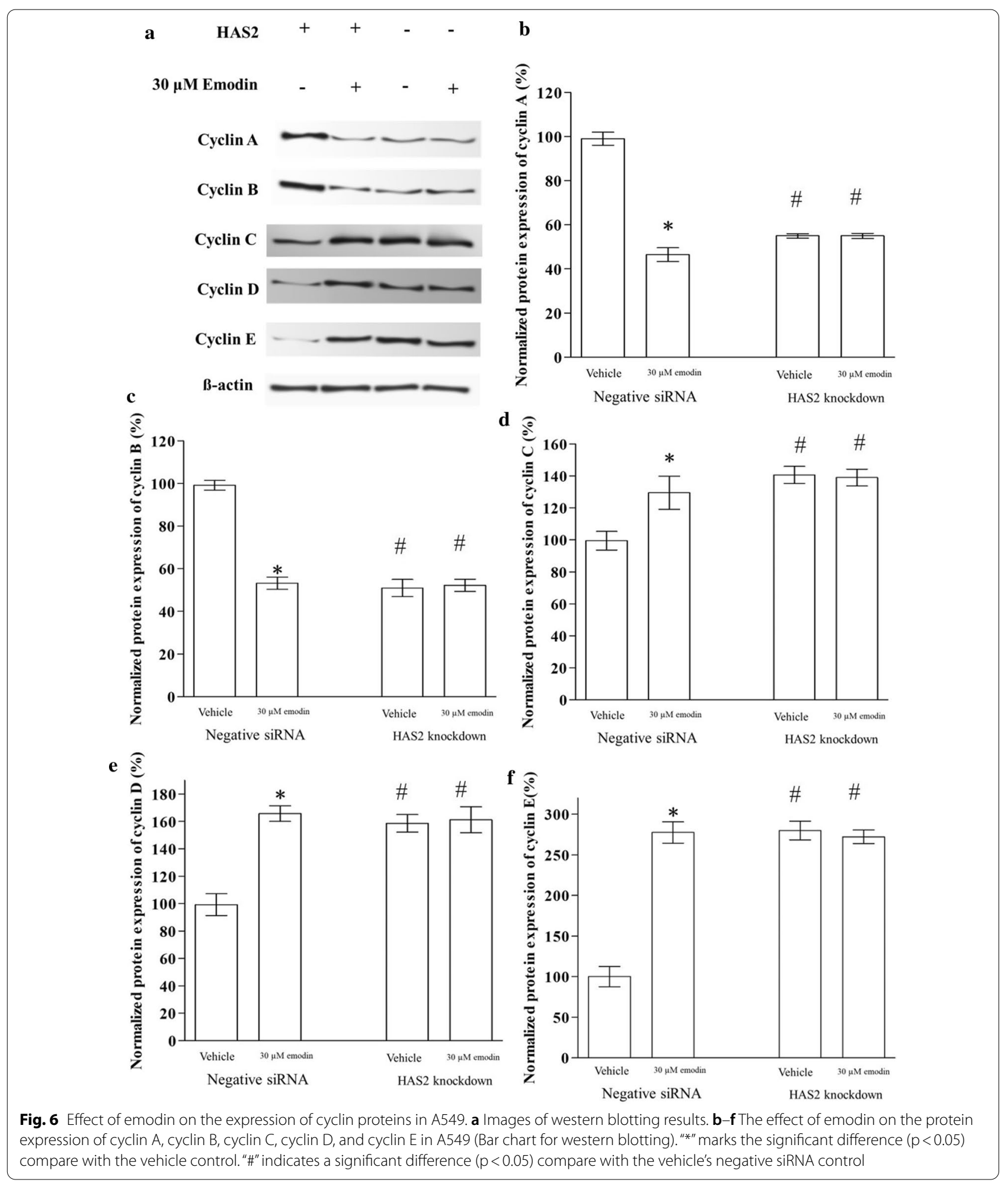

HAS2. cell cycle was the downstream targets of the emodin-HAS2-HA-CD44/RHAMM pathway. The subsequent study showed that the effect of the pathway on the cell cycle was mediated by cyclin proteins. As cyclin A regulates the $S$ phase [41] and cyclin $B$ regulates the G2 phase[42], emodin decreased cyclin A and B which 
results in the decrease in cells at the S/G2 phase. Cyclin $C$ was proved to suppressed cancer [43], it is also a downstream target of emodin found by this study. In terms of G1 phase regulators, we tested the cyclin D and cyclin E [44]. Our data revealed that both cyclin D and cyclin $\mathrm{E}$ raised after emodin exposure, which consistent with the increase in the G1 phase cells. These cyclin proteins were not changed by emodin exposure when HAS2 was knocked down suggesting that emodin affected the cell cycle through regulating HAS2. In addition, cancer stem cells might also play a role in the effect of emodin[45]. Considering the role of the HA in lung cancer, the potential effect of emodin might also involved cancer migration, some cell motility markers (FAK protein and MMPs) can be determined to explore the effect of emodin on cancer migration.

\section{Conclusions}

In balance, this study demonstrated that emodin suppresses non-small lung cancer cells by cell cycle regulation. We suggested that the HAS2-HA-CD44/RHAMM pathway is one of the pharmacological mechanisms of emodin, but whether HAS2 is a direct or indirect target is still unclear, more work regarding the upstream target of emodin is required. Given the clinical value of emodin as a potential anti-cancer drug, our study is conducive to the development of emodin as a novel therapeutic option for lung cancer.

\section{Abbreviations \\ NSCLC: Non-small cell lung cancers; HAS: Hyaluronan synthase; RHAMM: Hyaluronic acid-mediated motility.}

\section{Acknowledgements}

We thank the support of Natural Science Foundation of Liaoning Province.

\section{Authors' contributions}

ML performed the experiments and data analysis. SJ, YC, JX, and SZ, and ZL contributed to the design of experiment, writing, review and edition of the manuscript. All authors read and approved the final manuscript.

\section{Funding}

This work was financially supported by a grant from the Natural Science Foundation of Liaoning Province, China (NO. 2020-ZLLH-50).

\section{Availability of data and materials}

All data generated or analyzed during this study are included in this published article.

\section{Ethics approval and consent to participate}

This work was approved and consented by the Ethical Committee of Liaoning Cancer Hospital \& Institute.

\section{Consent for publication}

All the author consent for this publication.

\section{Competing interests}

There is no potential conflict of interest in this paper.

\section{Author details}

${ }^{1}$ Department of Integrated Traditional Chinese and Western Medicine Medical Oncology, Cancer Hospital of China Medical University, Liaoning Cancer Hospital \& Institute, Liaoning, China. ${ }^{2}$ Traditional Therapy Center, Liaoning TCM Hospital, Liaoning, China. ${ }^{3}$ Department of Gynecology, Cancer Hospital of China Medical University, Liaoning Cancer Hospital \& Institute, Liaoning, China. ${ }^{4}$ Department of Colorectal Surgery, Cancer Hospital of China Medical University, Liaoning Cancer Hospital \& Institute, Liaoning, China. ${ }^{5}$ Cancer Hospital of China Medical University, Liaoning Cancer Hospital \& Institute, Liaoning, China.

Received: 24 September 2020 Accepted: 10 December 2020

Published online: 06 January 2021

\section{References}

1. Torre LA, Siegel RL, Jemal A. Lung cancer statistics. Adv Exp Med Biol. 2016;893:1-19.

2. Skřǐčková J, Kadlec B, Vencliček O, Merta Z. Lung cancer. Casopis Lekaru Ceskych. 2018;157(5):226-36.

3. Herbst RS, Morgensztern D, Boshoff $C$. The biology and management of non-small cell lung cancer. Nature. 2018;553(7689):446-54.

4. Liu H, Xiong Y, Wang H, Yang L, Wang C, Liu X, Wu Z, Li X, Ou L, Zhang R, et al. Effects of water extract from epimedium on neuropeptide signaling in an ovariectomized osteoporosis rat model. J Ethnopharmacol. 2018;221:126-36.

5. Liu H, Xiong Y, Zhu X, Gao H, Yin S, Wang J, Chen G, Wang C, Xiang L, Wang $P$, et al. Icariin improves osteoporosis, inhibits the expression of PPARgamma, C/EBPalpha, FABP4 mRNA, N1ICD and jagged1 proteins, and increases Notch2 mRNA in ovariectomized rats. Exp Ther Med. 2017;13(4):1360-8.

6. Wu Z, Ou L, Wang C, Yang L, Wang P, Liu H, Xiong Y, Sun K, Zhang R, Zhu X. Icaritin induces MC3T3-E1 subclone14 cell differentiation through estrogen receptor-mediated ERK $1 / 2$ and p38 signaling activation. Biomed Pharmacother. 2017;94:1-9.

7. Chen G, Wang C, Wang J, Yin S, Gao H, Xiang LU, Liu H, Xiong Y, Wang $P$, Zhu X, et al. Antiosteoporotic effect of icariin in ovariectomized rats is mediated via the Wnt/beta-catenin pathway. Exp Ther Med. 2016;12(1):279-87.

8. Haixia W, Shu M, Li Y, Panpan W, Kehuan S, Yingquan X, Hengrui L, Xiaoguang L, Zhidi W, Ling O. Effectiveness associated with different therapies for senile osteopo-rosis: a network Meta-analysis. J Tradit Chin Med. 2020;40(1):17-27.

9. Yang Y-C, Lim M-Y, Lee H-S. Emodin isolated from Cassia obtusifolia (Leguminosae) seed shows larvicidal activity against three mosquito species. J Agric Food Chem. 2003;51(26):7629-31.

10. Naqvi S, Ullah M, Hadi S. DNA degradation by aqueous extract of Aloe vera in the presence of copper ions. Indian J Biochem Biophys. 2010;47(3):161-5.

11. Lee M-H, Kao L, Lin C-C. Comparison of the antioxidant and transmembrane permeative activities of the different Polygonum cuspidatum extracts in phospholipid-based microemulsions. J Agric Food Chem. 2011;59(17):9135-41.

12. Wang J-B, Zhao H-P, Zhao Y-L, Jin C, Liu D-J, Kong W-J, Fang F, Zhang L, Wang $\mathrm{H}-\mathrm{J}$, Xiao X-H. Hepatotoxicity or hepatoprotection? Pattern recognition for the paradoxical effect of the Chinese herb Rheum palmatum $L$ in treating rat liver injury. PloS one. 2011;6:9.

13. Wang M, Zhao R, Wang W, Mao X, Yu J. Lipid regulation effects of Polygoni Multiflori Radix, its processed products and its major substances on steatosis human liver cell line L02. J Ethnopharmacol. 2012;139(1):287-93.

14. Shrimali D, Shanmugam MK, Kumar AP, Zhang J, Tan BK, Ahn KS, Sethi G. Targeted abrogation of diverse signal transduction cascades by emodin for the treatment of inflammatory disorders and cancer. Cancer Lett. 2013;341(2):139-49.

15. Wei W-T, Lin S-Z, Liu D-L, Wang Z-H. The distinct mechanisms of the antitumor activity of emodin in different types of cancer. Oncol Rep. 2013;30(6):2555-62.

16. Zhang $X$, Chen Y, Zhang T, Zhang Y. Inhibitory effect of emodin on human hepatoma cell line SMMC-7721 and its mechanism. Afr Health Sci. 2015;15(1):97-100. 
17. Itano N, Sawai T, Yoshida M, Lenas P, Yamada Y, Imagawa M, Shinomura T, Hamaguchi M, Yoshida Y, Ohnuki Y, et al. Three isoforms of mammalian hyaluronan synthases have distinct enzymatic properties. J Biol Chem. 1999;274(35):25085-92.

18. Monslow J, Govindaraju P, Puré E. Hyaluronan - a functional and structural sweet spot in the tissue microenvironment. Front Immunol. 2015;6:231.

19. Turley EA, Noble PW, Bourguignon LY. Signaling properties of hyaluronan receptors. J Biol Chem. 2002;277(7):4589-92.

20. Toole BP. Hyaluronan-CD44 interactions in cancer: paradoxes and possibilities. Clin Cancer Res. 2009;15(24):7462-8.

21. Li XQ, Thonar EJ, Knudson W. Accumulation of hyaluronate in human lung carcinoma as measured by a new hyaluronate ELISA. Connect Tissue Res. 1989;19(2-4):243-53.

22. Pirinen R, Tammi R, Tammi M, Hirvikoski P, Parkkinen JJ, Johansson R, Böhm J, Hollmén S, Kosma VM. Prognostic value of hyaluronan expression in non-small-cell lung cancer: Increased stromal expression indicates unfavorable outcome in patients with adenocarcinoma. Int J Cancer. 2001;95(1):12-7.

23. Ko YH, Won HS, Jeon EK, Hong SH, Roh SY, Hong YS, Byun JH, Jung CK, Kang JH. Prognostic significance of CD44s expression in resected nonsmall cell lung cancer. BMC Cancer. 2011;11:340.

24. Wimmel A, Kogan E, Ramaswamy A, Schuermann M. Variant expression of CD44 in preneoplastic lesions of the lung. Cancer. 2001;92(5):1231-6.

25. Song JM, Im J, Nho RS, Han YH, Upadhyaya P, Kassie F. Hyaluronan-CD44/ RHAMM interaction-dependent cell proliferation and survival in lung cancer cells. Mol Carcinogenesis. 2019;58(3):321-33.

26. Li X, Peng B, Zhu X, Wang P, Xiong Y, Liu H, Sun K, Wang H, Ou L, Wu Z, et al. Changes in related circular RNAs following ERbeta knockdown and the relationship to rBMSC osteogenesis. Biochem Biophys Res Commun. 2017;493(1):100-7.

27. Li R, Xiao C, Liu H, Huang Y, Dilger JP, Lin J. Effects of local anesthetics on breast cancer cell viability and migration. BMC Cancer. 2018;18(1):666.

28. Liu X, Liu H, Xiong Y, Yang L, Wang C, Zhang R, Zhu X. Postmenopausal osteoporosis is associated with the regulation of SP, CGRP, VIP, and NPY. Biomed Pharmacother. 2018;104:742-50.

29. Liu H, Dilger JP, Lin J. Effects of local anesthetics on cancer cells. Pharmacol Ther. 2020;212:107558.

30. Foster KA, Oster CG, Mayer MM, Avery ML, Audus KL. Characterization of the A549 cell line as a type II pulmonary epithelial cell model for drug metabolism. Exp Cell Res. 1998;243(2):359-66.

31. Tang ZH, Jiang XM, Guo X, Fong CM, Chen X, Lu JJ. Characterization of osimertinib (AZD9291)-resistant non-small cell lung cancer $\mathrm{NCl}-\mathrm{H} 1975$ / OSIR cell line. Oncotarget. 2016;7(49):81598-610.

32. Guo W, Xie L, Zhao L, Zhao Y. mRNA and microRNA expression profiles of radioresistant $\mathrm{NCl}-\mathrm{H} 520$ non-small cell lung cancer cells. Mol Med Rep. 2015;12(2):1857-67

33. Giaccone G, Battey J, Gazdar AF, Oie H, Draoui M, Moody TW. Neuromedin B is present in lung cancer cell lines. Cancer Res. 1992;52(9 Suppl):2732s-2736s.
34. Lin DL, Chang C. p53 is a mediator for radiation-repressed human TR2 orphan receptor expression in MCF-7 cells, a new pathway from tumor suppressor to member of the steroid receptor superfamily. J Biol Chem. 1996;271(25):14649-52.

35. Kozaki K, Miyaishi O, Tsukamoto T, Tatematsu Y, Hida T, Takahashi T, Takahashi T. Establishment and characterization of a human lung cancer cell line NCl-H460-LNM35 with consistent lymphogenous metastasis via both subcutaneous and orthotopic propagation. Cancer Res. 2000;60(9):2535-40.

36. Chen YT, Chen Z, Du YN. Immunohistochemical analysis of RHAMM expression in normal and neoplastic human tissues: a cell cycle protein with distinctive expression in mitotic cells and testicular germ cells. Oncotarget. 2018;9(30):20941-52.

37. Sohr S, Engeland K. RHAMM is differentially expressed in the cell cycle and downregulated by the tumor suppressor p53. Cell Cycle. 2008;7(21):3448-60.

38. Liu H, Dilger JP, Lin J. The role of transient receptor potential melastatin 7 (TRPM7) in cell viability: a potential target to suppress breast cancer cell cycle. Cancers. 2020;12:1.

39. Dalton S, Coverdell PD. Linking the cell cycle to cell fate decisions. Trends Cell Biol. 2015;25(10):592-600.

40. Wang H, Chen Y, Zhai N, Chen X, Gan F, Li H, Huang K. Ochratoxin A-Induced Apoptosis of IPEC-J2 Cells through ROS-Mediated Mitochondrial Permeability Transition Pore Opening Pathway. J Agric Food Chem. 2017:65(48):04434

41. Ying H, Xiao Z-XJ. Targeting retinoblastoma protein for degradation by proteasomes. Cell Cycle. 2006;5(5):506-8.

42. Ma Y, Chen Y, Lin C, Hu G. Biological functions and clinical significance of the newly identified long non-coding RNA RP1-85F186in colorectal cancer. Oncol Rep. 2010;2:4.

43. Trakala M, Malumbres M. Cyclin C surprises in tumour suppression. Nat Cell Biol. 2014;16(11):1031-3.

44. Keenan SM, Lents NH, Baldassare JJ. Expression of cyclin E renders cyclin D-CDK4 dispensable for inactivation of the retinoblastoma tumor suppressor protein, activation of E2F, and G1-S phase progression. J Biol Chem. 2004:279(7):5387-96.

45. A prospective for the potential effect of local anesthetics on stem-like cells in colon cancer. https://medicalresearchjournal.org/index.php/ GJMR/article/view/1971.

\section{Publisher's Note}

Springer Nature remains neutral with regard to jurisdictional claims in published maps and institutional affiliations.
Ready to submit your research? Choose BMC and benefit from:

- fast, convenient online submission

- thorough peer review by experienced researchers in your field

- rapid publication on acceptance

- support for research data, including large and complex data types

- gold Open Access which fosters wider collaboration and increased citations

- maximum visibility for your research: over $100 \mathrm{M}$ website views per year

At BMC, research is always in progress.

Learn more biomedcentral.com/submissions 